\title{
On Untranslatability of English Linguistic Humor
}

\author{
Qian Han \\ Dalian University of Technology, Dalian, China \\ Email: hanqian74@sina.com
}

\begin{abstract}
Linguistic humor has long been considered untranslatable because of the fact that its linguistic features can never be duplicated in another language. The thesis views this long-debated issue with the Skopos theory and Translation Variation Theory and arrives at the conclusion that what has been hindering the humor translation includes not only the outward form-linguistic features of humor, but also something in ideological aspect - the conventional idea about the nature of translation and translation criteria.
\end{abstract}

Index Terms - untranslatability, linguistic feature, ideological aspect

\section{INTRODUCTION}

Numerous scholars hold the view that English linguistic humor is impossible to be translated into Chinese because English, as an alphabetic language, makes full use of its own phonological, semantic and syntactic features in producing linguistic humor that are practically impossible to be duplicated in Chinese, which is an ideographical language. It is reasonable, but only partly right. In most cases the conventional concept about translation and translation criteria hinders translation more than linguistic features do.

With people's gradually enriched knowledge about the nature of translation, translation criteria are undergoing a transformation from being unitary to being multiple. In the meanwhile new theories and approaches keep emerging and give us strong theoretical support to approach the translation of linguistic humor from English to Chinese in different ways. It is high time we reconsidered the issue from new perspectives.

\section{THE FEATURES OF ENGLISH LINGUISTIC HUMOR}

Humor involves different modes and falls into different groups if viewed from different angles and for different purposes. Linguistic humor is the rhetoric device-dependent humor, whose funny effect derives directly from the language itself due to the clever use of rhetorical devices like pun, zeugma and so on. So it is almost the same as the comic created by language. As far as English linguistic humor is concerned, it adopts rhetorical devices in phonological, semantic and syntactic approaches. For example, (1) "We have courses to make grown men young and young men groan". (2) A: Please put on your clothes. I don't want to see you in front of me without wearing anything. B: I'm wearing the perfume. (3) A: There is a man outside with a wooden leg named Smith. B: What is the name of his other leg? English makes best use of its homophonic words or phrases, polyphones, polysemants, homographs, perfect homonyms and full homonyms to create humor. Phonetic features are usually coupled with semantic ones to add a charming flavor to a humorous writing. Linguistic untranslatability occurs when the linguistic form has a function beyond conveying factual relationships.

\section{UNTRANSLATABILITY OF ENGLISH LINGUISTIC HUMOR}

A prevailing opinion that linguistic humor is unlikely to be translated into another language has long been dominating the translation field. The untranslatability lies in the fact that English and Chinese belong to the different language families and the linguistic differences are almost insurmountable.

Take the above humor for example. Humor (1) "We have courses to make grown men young and young men groan". The meaning can be easily put across into Chinese but the link between "grown" and "groan", which is reflected in the pronunciation, definitely disappears in the translation. Humor (2) is a humor using semantic feature of the word "wear". It can be followed by different objects, so in English there exist several different expressions with it like "to wear a dress", "to wear earrings", "to wear arms", "to wear an air of expectancy", "to wear a beard", and "to wear a hole in the sole". But when they are translated into Chinese, six different Chinese words are needed to explain the same English word “wear”: “穿着一件裙子”, “戴着耳环”, “佩戴着武器”, “面带期望的神色”, “蓄着胡子”, and “鞋底磨了个洞”, The semantic feature of "wear" makes this joke possible in English but practically untranslatable into Chinese. In the third humor, the phrase "named Smith" is the attribute of "a man". But they are separated by another phrase "with a wooden leg". So "named Smith" can be taken as the attribute of "a wooden leg", too. Because of the syntactic ambiguity, humorous effect is easily achieved in English but it is difficult in Chinese. 
Some researchers think linguistic humor can only be produced and consumed at home, without any possibility to be translated into other languages or other characters. So compared with other fields, the study on humor translation, especially linguistic humor E-C translation, is still a runner-up.

An investigation was carried out in September, 2007 about linguistic humor E-C translation in China. Thirteen core journals in foreign language learning/teaching and translation fields have been searched, including four well known professional translation journals, via the data bank, China Academic Journals (CAJ) of China National Knowledge Infrastructure (CNKI). For each journal, "theme" was selected as the search item and “幻默” as the search word and time is from 1985 to 2007 . The result is illustrated in the following tables.

TABLE. 1

THE INVESTIGATION ON HUMOR STUDIES IN CHINA (1985-2007)

\begin{tabular}{|l|l|l|}
\hline \multicolumn{2}{|l|}{ The Title of the Journal } & Article \\
\hline 1 & Journal of Foreign Languages & 17 \\
\hline 2 & Foreign Languages and Their Teaching & 13 \\
\hline 3 & Modern Foreign Languages & 7 \\
\hline 4 & Journal of PLA University of Foreign Languages & 20 \\
\hline 5 & Foreign Language Research & 12 \\
\hline 6 & Foreign Language Education & 21 \\
\hline 7 & Foreign Languages Research & 3 \\
\hline 8 & Journal of Sichuan International Studies University & 25 \\
\hline 9 & Shandong Foreign Language Teaching Journal & 5 \\
\hline 10 & Language and Translation & 4 \\
\hline 11 & Shanghai Journal of Translators for Science and Technology & 1 \\
\hline 12 & Chinese Science \& Technology Translators Journal & 4 \\
\hline 13 & Chinese Translators Journal & 11 \\
\hline
\end{tabular}

Tab.1 shows that 143 articles on humor have been published in these 13 journals up to the date of September 1, 2007. The number of 143 is desperately small in contrast to more than 20 years of time span.

Then those 143 articles were reexamined and articles with humor translation as the subject were singled out. The result is more unsatisfactory.

TABLE. 2

THE INVESTIGATION ON HUMOR TRANSLATION STUDIES IN CHINA

\begin{tabular}{|l|l|l|l|}
\hline & The Title of the Journal & Article & Publishing Time \\
\hline 1 & Journal of Foreign Languages & 1 & $1992 / 01$ \\
\hline 2 & Foreign Languages and Their Teaching & 1 & $2007 / 02$ \\
\hline 3 & Modern Foreign Languages & 0 & $/$ \\
\hline 4 & Journal of PLA University of Foreign Languages & 2 & $2007 / 02 ; 1996 / 06$ \\
\hline 5 & Foreign Language Research & 0 & $/$ \\
\hline 6 & Foreign Language Education & 5 & $2002 / 05 ; 1994 / 02 ; 1990 / 02 ; 1987 / 01 ; 1987 / 03$ \\
\hline 7 & Foreign Languages Research & 0 & $/$ \\
\hline 8 & Journal of Sichuan International Studies University & 2 & $2007 / 02 ; 1998 / 01$ \\
\hline 9 & Shandong Foreign Language Teaching Journal & 0 & $/$ \\
\hline 10 & Language and Translation & 1 & $1985 / 04$ \\
\hline 11 & Shanghai Journal of Translators for Science and Technology & 1 & $1993 / 03$ \\
\hline 12 & Chinese Science \& Technology Translators Journal & 1 & $2004 / 04$ \\
\hline 13 & Chinese Translators Journal & 2 & $2002 / 01 ; 1999 / 03$ \\
\hline
\end{tabular}

Two problems reflected in Tab. 2 deserve our attention.

First, only 16 articles among 143 are about humor translation and these 16 articles include those in which humor is not the only subject. Second, the publishing year is not near. It reflects that not much new research has been done into humor translation.

Linguistic features of English humor are undoubtedly factors that hinder the translation, but are there any other reasons besides those in linguistic aspect? This is the question that deserves our deep thought.

\section{RECONSIDERATION OF UNTRANSLATABILITY AND TRANSLATABILITY OF LINGUISTIC HUMOR}

What is translatability and untranslatability? Baker defines it as the capacity for some kind of meaning to be transferred from one language to another without undergoing radical change (Baker, 1998). Owing to the fact that the concept of "meaning" varies greatly among different scholars and researchers, the definition of translatability itself remains a vague concept. 
When it comes to linguistic humor translation, no one can deny that peculiar linguistic features of English linguistic humor block the way of its translation. But Chang Nam Fung's statement on pun translation gives us an idea about the true reason that is deeply hidden. Chang (2003) says to the effect that translatability varies greatly with the changes of the views to what is translation. The fact that linguistic humor has long been considered untranslatable is greatly due to the conventional concept about the nature of translation and translation criteria.

The topic of translation criterion is one that has arisen ever since the emergence of translation activities. Traditional translation theory in China emphasizes faithfulness which means the precise conveyance of the message must be given priority. People use "accuracy" to evaluate a translation and to judge the extent to which the translation matches its original. But the fact is not every word in one language has an exact equivalent in another and not all concepts that are expressed through the words of one language are identical to the ones that are expressed through the words of another. Traditional criteria are usually aware of the intra-linguistic factors such as semantic, lexical, grammatical features but attach little importance to extra-linguistic factors like situation, subject field and receiver.

$\mathrm{Gu}$ Zhengkun held that it is the unilateralism of our thoughts that makes us accustomed to judging things by A or B. People are used to believing that everything has a unique answer, affected by which many translators have spared no efforts looking for an absolutely right translation criterion (Gao, 2007). This is the exact way people view English linguistic humor translation and the very reason that the idea of untranslatability is widely accepted. So we need to consider the issue from the ideological aspect.

In his book A Study on Translation Compensation, Xia Tingde (2006) analyzes the translatability and untranslatability by citing how Feng Youlan explained the hard understanding Chinese proposition, "A hoop-linked chain can be unlinked (连环可解也) ”, raised by Hui Shi who was a well-known Chinese debater of 2000 years ago. This proposition is hard to understand because people always wonder: Now that it is a hoop-linked chain, how can it be unlinked? Feng Youlan broke the usual thinking mode and viewed the proposition from a new angle: once a hoop-linked chain was damaged, it would be easily unlinked. The lesson we can learn is that why not stop inviting desperation and approach linguistic humor E-C translation in other ways?

The answer lies in the Skopos theory and Translation Variation Theory. Functionalists have moved away from the linguistically oriented translation theory because linguistics alone won't help us. It reflects a general shift from predominantly linguistic and rather formal translation theories to a more functional and sociocultural oriented concept of translation. The significance of Skopos theory in linguistic humor translation is that it sets it free from the restriction of the conventional idea that translations must be faithful to the source texts in linguistic form, for it redefines equivalence as the same communicative function or functions as the source text.

In addition, Translation Variation Theory put forward by Huang Zhonglian in 2001 brings new lights to Chinese translation studies. Translation variation refers to translation activities where various shifting devices, such as adding, reducing, editing, narrating, contracting, combining, rewriting, are employed (黄忠廉, 2002). It is of great significance for both the theoretical study of translation and translation practice in China, because it formally includes those so-called non-translational methods into the framework. So it has a great influence on linguistic humor translation by providing theoretical support to those who carry out translation activities with devices unacceptable before. For example, (4) A: What makes a road broad? B: The letter "B". If there were no Translation Variation Theory, the translation should be like this: 甲：为什么路会变宽？乙：因为字母 B。 It seems that the translation is faithful to the source text, but in fact humor dies out totally in the target text. Now with this theory, we can translate the source text this way:甲：什么会使门变阔？乙: “活”字呗！ This Chinese translation that used to be unacceptable is now a good illustration of compensation, one of translation methods.

Now that the criteria judging a good translation have become multiple from unitary, many methods prove workable in translating English linguistic humor. Peter Newmark (1998) tackled the problem of pun translation by putting forward "compensation". If the purpose of the pun is merely to raise laughter among its readers, it could sometimes be compensated by another pun on a word with a different but associated meaning. Leo Hickey (2001) wrote in Perlocutionary Equivalence: Marking, Exegesis and Recontextualization that recontextualization applied well to translating humorous writings. Chinese scholars managed to put forward some solutions, too. Zhao Yanchun(2005) thinks analogy is a method to solve the problem. Chang Nam Fung (2003) put forward ten methods of translating pun after analyzing Delabastita's strategies on pun translation ( Pun is a major rhetorical device used to create humor. Solutions to pun translation must be much helpful to humor translation).

\section{CONCLUSION}

The long-debated issue of translatability and untranslatability accompanies the development of translation theory and practice. Linguistics and translation have long had what Peter Fawcett calls a love- hate relationship. In the era when new theories keep emerging, it is necessary and imperative that linguistic humor translation criteria be re-oriented and that the contribution of linguistic approaches be placed in a more realistic perspective if we want to find out a solution to the translation of linguistic humor from English to Chinese. 
[1] Baker, Mona. (1998). Routledge Encyclopedia of Translation Studies. London and New York: Routledge.

[2] Gao Yajuan. (2007). A Study on the Indeteerminacy of Translation Thesis and Translation Criteria. Nanjing Normal University.

[3] Hickey, Leo. (2001). Perlocutionary Equivalence: Marking, Exegesis and Recontextualization. Shanghai: Shanghai Foreign Language Education Press.

[4] Newmark, Peter. (1998). A Textbook of Translation. Shanghai: Shanghai Foreign Language Education Press.

[5] Huang Zhonglian. (2002). Translation Variation Theory. China Translation \& Publishing Corporation.

[6] Xia Tingde. (2006). A Study on Translation Compensation. Hubei: Hubei Education Press.

[7] Chang Nam Fung. (2003). The Application of Delabastita's Theory of Pun Translation to English-Chinese Translation. Chinese Translators Journal.

[8] Zhao Yanchun. (2005). A Reductionist Approach to Translatology. Shanghai: Shanghai Foreign Language Education Press.

Qian Han was born in Jinzhou, China in 1974. She received her M. A. degree in linguistics from Dalian University of Technology, China in 2008.

She is currently a lecturer in the School of Foreign Languages, Dalian University of Technology, Dalian, China. Her research interests include translation study and FLT. 